\title{
ERIC WEIL: O HEGELIANISMO FRANCÊS E A QUESTÃO DO SENTIDO *
}

\author{
Eric Weil: french hegelianism and the question of meaning
}

Judikael Castelo Branco **

Evanildo Costeski ***

Resumo: Neste artigo refletimos sobre a filosofia como "ciência do sentido" e sobre a tarefa do filósofo a partir do pensamento de Eric Weil. Para tanto, retomamos a relação de Weil com a filosofia francesa contemporânea e seu papel na introdução de Hegel na França. Depois, acompanhamos o seu juízo sobre tentativas de superação do hegelianismo, ocupando-nos de escritos de Weil sobre o existencialismo e sobre as interpretações de Sartre, Alquié e Étiemble para o pensamento de Marx. Por fim, colocamo-nos diante do problema capital da filosofia weiliana: a violência. $O$ desafio de Weil é pensar o sentido da filosofia depois do discurso hegeliano do Absoluto, de um lado, e da "violência total" de Hitler, de outro. A relevância da questão se justifica pela própria tessitura do nosso atual cenário político e intelectual. Tornar-se mais uma vez urgente insistir sobre o valor do esforço do filósofo na luta contra a violência.

Palavras-chaves: Filosofia francesa. Hegelianismo. Sentido. Violência.

Abstract: In this article we reflect on philosophy as a "science of meaning" as well as on the philosopher's task based on Eric Weil's thinking. To do so, we first return to Weil's relationship with contemporary French philosophy and his

\footnotetext{
* Artigo recebido em 18/02/2020 e aprovado para publicação em 30/06/2020.

** Duplo doutorado em Filosofia pela Universidade Federal do Ceará (UFC) e pela Université Charles de Gaulle (Lille 3) (Fraça). Atualmente, professor efetivo; publicação em 30/06/2020. *** Evanildo Costeski: Doutor em Filosofia pela Pontificia Università Gregoriana (PUG) (Roma). Professor efetivo do Departamento de Filosofia da Universidade Federal do Ceará (UFC).
} 
role in introducing Hegel in France. Then, we follow his judgment on attempts to overcome Hegelianism, by examining his writings on existentialism and on Sartre, Alquié and Étiemble's interpretations of Marx's thought. Finally, we address the main question of Weilian philosophy: violence. Weil's challenge is to think philosophy after the Hegelian discourse of the Absolute, on the one hand, and Hitler's "total violence", on the other. The relevance of the topic is justified by the very structure of our current political and intellectual scenario. Once again it is urgent to insist on the value of the philosopher's effort to fight against violence.

Keywords: French Philosophy. Hegelianism. Sens. Violence.

\section{Introdução}

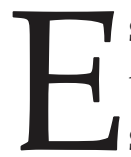
ste artigo trata da filosofia em Eric Weil, isto é, toca em última instância a sua compreensão da atividade do filósofo no mundo em que se ouviu o anúncio do "evangelho da violência pura". ${ }^{1}$ Dito de outro modo, nós nos perguntamos, com Weil, sobre a natureza da filosofia e sobre a tarefa do filósofo numa época, a nossa, em que a própria reflexão sobre o sentido tem o seu significado radicalmente questionado. De um lado, isso nos prende a mais genuína tradição filosófica ocidental, tradição que não cessou de buscar definir e justificar a presença da filosofia entre os fazeres humanos; de outro, esse exercício nos confronta diretamente com questões absolutamente atuais num cenário de hegemonia do conhecimento tecnicista ou, nas palavras de Eric Weil, da "razão delirante". ${ }^{2}$

O tema já foi tratado por Giusi Strummiello, a partir de outra perspectiva. ${ }^{3}$ Decidimos abordá-lo em três momentos distintos, a nosso ver, fundamentais à compreensão das questões que visamos. Em primeiro lugar, retomamos a relação de Eric Weil com o pensamento francês do último século, mais precisamente com a introdução da obra de Hegel na filosofia francesa. Um brevíssimo panorama da filosofia francesa contemporânea, bem como o conhecimento da sua formação junto a Cassirer e da sua aproximação a Koyré e Kojève, nos ajudam a ter em conta o quadro das questões a partir das quais Weil articula a própria compreensão da natureza da filosofia e da função social do filósofo. No entanto, esse quadro só se completa de fato se consideramos o que significa, para Eric Weil, o esforço de pensar o sentido da filosofia depois do discurso hegeliano do Absoluto, no plano

\footnotetext{
${ }^{1}$ WEIL, E. L'avenir de la philosophie. In QUILLIEN, J. (Org.), Cahiers Eric Weil I. Lille: Presses Universitaires de Lille, 1987, p. 16.

${ }^{2}$ WEIL, E. Logique de la philosophie. Paris: Vrin, 1998, p. 17.

${ }^{3}$ Cf. STRUMMIELLO, G. Filosofia e metafilosofia in WEIL, E. Violenza e libertà. Milano: Mimesis, 2006, p. 101-119.
} 
filosófico", e depois da "violência total" de Hitler nos domínios da história e da política. ${ }^{5}$

Em segundo lugar, procuramos o juízo de Weil sobre algumas tentativas de filósofos franceses de superação do hegelianismo. Privilegiamos escritos nos quais Eric Weil fala de forma explícita da sua interpretação do existencialismo e de leituras francesas das obras de Marx. Nesse conjunto, ficam destacadas as suas críticas ao existencialismo francês bem como à interpretação que Sartre, Alquié e Étiemble propõem para alguns conceitos centrais do marxismo. Para Weil, resumidamente, o existencialismo é insuficiente por sua incapacidade de compreender uma totalidade concreta e, àquela altura, as interpretações de Marx pecavam por não saberem distinguir teoria e prática, o que é absolutamente fundamental no pensamento marxiano.

Por fim, Weil nos põe diante do problema constitutivo do seu modo de pensar: a violência. A questão fundamental é então como compreender a filosofia depois de Hegel e qual o fundamento da sua razoabilidade depois de Hitler. Em outras palavras, é ainda possível um sentido para a filosofia? O que torna Hegel incontornável para Weil é a sua articulação de um discurso absolutamente coerente; o problema nasce quando a história, a nossa história, comprova a possibilidade de uma recusa igualmente absoluta do discurso. Qual seria então a justificativa da ação do filósofo? Haverá para ele alguma garantia de sucesso? De um modo ainda mais radical, há algum futuro para a filosofia?

Essas perguntas estão espalhadas na obra weiliana e a sua atualidade não precisa ser justificada a quem olha atentamente para o nosso quadro atual. Resta por isso insistir com ele sobre o valor do esforço do filósofo, da sua luta contra a violência e a insensatez, e sobre a sua responsabilidade em tempos de desconforto intelectual, mas acima de tudo de intranquilidade social, política e moral. ${ }^{6}$

\section{Eric Weil e o hegelianismo na filosofia francesa contemporânea}

Em seus primeiros trabalhos, Eric Weil se interessou especificamente pela filosofia da Renascença italiana, pesquisando inicialmente, sob a orientação de Ernest Cassirer, o pensamento de Pietro Pomponazi ${ }^{7}$, e em seguida, na

\footnotetext{
${ }^{4}$ Cf. CASTELO BRANCO, J.; COSTESKI, E. Observações sobre o hegelianismo de Éric Weil. In WEIL, E. Hegel e nós. Caxias do Sul: EDUCS, 2019, p. 17-34.

${ }^{5}$ A expressão "violência total" se encontra em WEIL, E. Logique de la philosophie, op. cit. p. 354.

${ }^{6}$ Cf. WEIL, E. L'avenir de la philosophie, op. cit. p. 21.

7 WEIL, E. La philosophie de Pietro Pomponazzi. Pic de la Mirandole et la critique de l'astrologie. [Trad. G. Kircher; J. Quillien]. Vrin, Paris, 1985.
} 
Bibliothek Warburg, a obra de Marsílio Ficino. ${ }^{8}$ Em 1933, o filósofo deixou a Alemanha e se estabeleceu definitivamente na França, onde, com a direção de Alexandre Koyré, apresentou uma dissertação sobre Pico della Mirandola. ${ }^{9}$ Mas foi somente a partir da publicação de Logique de la philosophie juntamente com Hegel et l'État, em 1950, e depois com Philosophie politique, em 1956, e Philosophie morale, em 1961, que Eric Weil assumiu o próprio espaço no cenário filosófico do século passado. ${ }^{10}$ Para o nosso objetivo, sumariar esse itinerário é interessante para compreender o lugar que o filósofo ocupa no contexto da filosofia francesa contemporânea.

Acompanhando Alain Badiou, chamamos "filosofia francesa contemporânea" a reflexão desenvolvida na França na segunda metade do século $\mathrm{XX}$, mais precisamente entre a publicação de L'être et le néant, de Jean-Paul Sartre, em 1943, e Qu'est-ce que la philosophie?, de Gilles Deleuze e Félix Guattari, de 1991. Nestes cinco decênios, nomes como Bachelard, Merleau-Ponty, Lévi-Strauss, Althusser, Foucault, Derrida e Lacan, nos fazem pensar nesse período como "um momento filosófico novo, criador, singular e ao mesmo tempo universal". Com efeito, a partir dos trabalhos de autores tão díspares, a filosofia francesa assumiu um status especial no plano internacional, distinguindo-se, na sua essência, da filosofia praticada em outros lugares, e isso se refere tanto à compreensão, quanto à prática e ao modo concreto da filosofia.

Um ponto incontornável - e talvez menos considerado que a "originalidade" do pensamento francês contemporâneo - é o fato de que nesse período específico os filósofos franceses mais conhecidos se apoiem em filósofos alemães, especialmente em Hegel, Nietzsche, Husserl e Heidegger. Badiou, identificando as operações intelectuais comuns aos filósofos franceses, caracteriza antes de tudo "uma operação alemã", ou mais exatamente

\footnotetext{
${ }^{8}$ WEIL, E. Ficin et Plotin. [Trad. A. Deligne; M. Engelmeier]. Paris: L'Harmattan, 2007.

${ }^{9}$ A dissertação Pic de la Mirandole et la critique de l'astrologie foi defendida na École Pratique des Hautes Études, em 03 de abril de 1938, e além de Koyré como diretor, teve Henry Corbin e Paul Vignaux como examinadores. Cf. WEIL, E. La philosophie de Pietro Pomponazzi. Pic de la Mirandole et la critique de l'astrologie. op. cit.

${ }_{10}$ Acerca da recepção da Logique, podemos retomar os testemunhos de François Châtelet quando diz que a "Logique de la philosophie, (...) é certamente, na perspectiva da filosofia especulativa, a obra mais profunda que foi publicada na França em 50 anos", cf. CHÂTELET, F. Chronique des idées perdues. Paris: Stock, 1977, p. 105; ou de Jean Wahl para quem "a erudição e a profundidade que marcam essa tentativa [de alargar a visão hegeliana considerando o fato de que esta história do pensamento não parou em Hegel] fazem da obra de Eric Weil, Logique de la philosophie, uma das mais importantes do pensamento contemporâneo na França", cf. WAHL, J. Tableau de la philosophie française. Paris: Gallimard, 1962, p. 174-175. A reação de Kojève à leitura do livro ficou registrada em carta a Leo Strauss: "Weil terminou seu grande livro. Muito impressionante. Além de muito 'Hegelo-Marxista' e certamente influenciado por meu curso. Mas ele termina à la Schelling: poesia - filosofia, e sabedoria como silêncio. Finalmente terminei de lê-lo. Arrependo-me de não tê-lo escrito eu mesmo", cf. STRAUSS, L. On tyranny. Including the Strauss-Kojève correspondence. Chicago: University Chicago Press, 2000, p. 234-239.
} 
"uma operação francesa direcionada para os filósofos alemães", afirmando acertadamente que "toda a filosofia francesa da segunda metade do século XX é, na realidade, também uma discussão sobre o legado [filosófico] alemão". ${ }^{11}$ Essa operação se constitui em dois momentos essenciais. Em primeiro lugar, entre 1933 e 1939, tem-se o famoso curso de Alexandre Kojève sobre Hegel na École des Hautes Études. Em segundo lugar, há a descoberta da fenomenologia de Husserl e de Heidegger nas décadas de 30 e $40 .{ }^{12}$ Eric Weil se insere precisamente na introdução de Hegel em solo francês, contribuindo, então, para a superação do tempo em que se tinha "horror da dialética", segundo a descrição de Sartre..$^{13}$

A abordagem da relação de Weil com o pensamento francês do último século, no que concerne ao seu papel na apresentação de Hegel na França, exige duas perspectivas diferentes, ambas propriamente filosóficas. De um lado, tomamos o argumento numa leitura da história para esboçar o quadro no qual a relação de Weil com o cenário da filosofia francesa se desenvolve e no qual é percebido; de outro, procuramos uma leitura sistemática, entendida justamente como o antônimo de um ponto de vista puramente histórico.

No que diz respeito à história, Weil desde a sua chegada à França acompanha a introdução do pensamento hegeliano nas margens do Sena. ${ }^{14} \mathrm{Com}$ efeito, seu nome figura juntamente com Alexandre Koyré e Alexandre Kojève como os filósofos estrangeiros que desempenharam papel fundamental na apresentação da Filosofia do direito, da Filosofia da História e da Fenomenologia do Espírito do mestre de Berlim ao público francês. ${ }^{15}$ Em grande medida, Weil parece ter procurado essa associação a Kojève e Koyré. É o que tes-

${ }^{11}$ BADIOU, A. Panorama de la philosophie française contemporaine. Eikasia Revista de Filosofia 3 (2006), p. 4-5.

${ }_{12}$ Os artigos de Emmanuel Lévinas na Revue Philosophique, sobre Heidegger, em 1932, e Husserl, em 1940, são testemunhas desse "segundo momento essencial". Com efeito, ao retomá-los no livro En découvrant l'existence avec Husserl et Heidegger, Lévinas - limitando-se ao existencialismo na França - reconhece que, "gostemos ou não, os temas introduzidos por Heidegger abriram ao pensamento filosófico novas possibilidades ou deram um sentido novo às suas antigas possibilidades. E o existencialismo francês - exceto talvez Gabriel Marcel depende largamente da fenomenologia, embora só se tenha nutrido com a parte antropológica do pensamento heideggeriano, daquela filosofia da existência que Heidegger não deseja para si", cf. LÉVINAS, E. En découvrant l'existence avec Husserl et Heidegger. Paris: Vrin, 2006, p. 8. ${ }^{13}$ SARTRE, J.-P. Critique de la raison dialectique. Précédé de Questions de méthode. Tome I. Paris: Gallimard, 1985, p. 28

${ }^{14}$ Acerca da introdução do pensamento hegeliano na França, cf. JARCZYK, G. - LABARRIÈRE, P.-J. De Kojève à Hegel. 150 ans de pensée hégélienne en France. Paris: Albin Michel, 1996, p. 17-40.

${ }^{15}$ Nesse processo, sobretudo a partir da publicação de Hegel et l'État, o papel de Weil é reconhecido por grandes intérpretes da obra hegeliana, como, por exemplo, Labarrière e Bourgeois. Por isso, causa certa estranheza a completa ausência do seu nome no capítulo intitulado justamente "O hegelianismo francês", do livro de Robert Sinnerbrink, cf. SINNERBRINK, R. Hegelianismo. [Trad. F. Creder]. Petrópolis: Vozes, 2017, p. 179-284. 
temunham, por exemplo, a sua participação nos famosos seminários do primeiro sobre a Fenomenologia, bem como a dedicatória da Logique de la philosophie ao segundo. Porém, se esses dados são tão conhecidos que a referência a eles acrescenta pouco ao nosso argumento, podemos remontar também às palavras de Livio Sichirollo:

O que não é conhecido - e podemos dizer agora, penso que não seja indiscreto -, é que a Introdução [à leitura de Hegel] nasceu na casa de Weil. Kojève sabia que não conhecia Hegel como Koyré e Weil e, além disso, ele só tinha um verão para se preparar. Teve então a preocupação de procurar as pessoas de que precisava. Weil também sabia encontrar interlocutores à sua altura, pela cultura, pela inteligência e pela capacidade de ler um texto. E foram discussões acaloradas, intermináveis, de noites inteiras. ${ }^{16}$

Ao que se acrescenta em seguida: "Kojève era fascinante como homem e como pensador. Weil o apreciava, gostava de discutir com ele, mas não compartilhava sequer uma única palavra de suas teses hegelianas" ${ }^{17}$ É nesse ponto que, a nosso ver, surge o problema, pois a partir da sua relação com a obra de Hegel e com pensadores hegelianos, muitas vezes Weil é considerado simplesmente como intérprete de Hegel.

Mas se Alexandre Kojève é hegeliano, ainda que de um modo muito peculiar, a questão que fazemos é se, por sua filosofia, Eric Weil também pode ser definido desse modo. Em outras palavras, inquirimos se o adjetivo "hegeliano" é suficiente para caracterizar o pensamento de Eric Weil. Portanto, nosso problema vai de encontro a reações como, por exemplo, a de Emmanuel Lévinas ${ }^{18}$, ou a do próprio Kojève quando em Le Concept, le Temps et le Discours reconhece o valor de Weil nesses termos: "Quanto ao que concerne à minha atualização de Hegel, é a influência de Eric Weil que devo mencionar, pois foi através dele que tive contato com o moderno neopositivismo do Discurso (logos). Mas, antes de tudo um bom hegeliano, tomou também um caminho que não sei para onde leva" ${ }^{19}$

\footnotetext{
${ }^{16}$ SICHIROLLO, L. La dialettica degli antichi e dei moderni. Bologna: Il Mulino, 1997, p. 19-20.

${ }^{17}$ Idem, p. 20.

${ }^{18}$ LÉVINAS, E. En découvrant l'existence avec Husserl et Heidegger, op. cit. p. 189. Depois de caracterizar a filosofia hegeliana como uma redução do outro, acrescenta: "um dos mais profundos intérpretes modernos do hegelianismo, Eric Weil, admiravelmente o exprimiu na sua Logique de la philosophie mostrando como cada atitude do ser razoável se transforma em categoria, quer dizer, se percebe numa nova atitude. Mas ele pensa, conforme à tradição filosófica, que o resultado é uma categoria que absorve todas as atitudes". Essa conclusão é suficiente para afirmar que Lévinas não compreendeu de fato a proposta de Weil da lógica da filosofia como "filosofia primeira", cf. Idem, p. 263-264.

${ }^{19}$ KOJÈVE, A. Le Concept, le Temps et le Discours. Paris: Gallimard, 1983, p. 33. Para evitar equívocos na interpretação dos termos referentes ao "moderno neopositivismo do Discurso", tomamos as palavras de Luís Manuel Bernardo ao explicá-los deste modo: "o que é, eventualmente, mais problemático é a inclusão da proposta de Weil na corrente neopositivista do discurso $(\log o s)$. No entanto, o facto de ter havido o cuidado de pôr o termo grego entre parêntesis mostra que não se trata da designação de uma corrente, mas da indicação de uma
} 
Eric Weil não foi um "bom hegeliano" só para Kojève; Francesco Valentini, num livro intitulado precisamente La filosofia francese contemporanea, de 1958, toma a obra weiliana apontando para o seu "hegelianismo" iniciando justamente com a afirmação de que há, em Weil, um "retorno a Hegel". ${ }^{20}$ Essa mesma perspectiva marcou a recepção inicial de Weil no Brasil como vemos, por exemplo, na recensão da Philosophie politique feita por Carlos Lopes de Mattos ${ }^{21}$-, e se estendeu a leituras mais recentes, como a de Agemir Bavaresco e Danilo Costa que listam o nome de Eric Weil, sem mais, entre "hegelianos ortodoxos". ${ }^{22}$

Porém, a oração de Kojève reconhece igualmente um outro aspecto, quer dizer, considera também o fato de que Weil tomou um caminho desconhecido ao autor de Introduction à la lecture de Hegel. É este o terreno próprio da questão, é nele que devemos recordar os termos com os quais,

forma de compreender o discurso, nomeadamente, na sua relação com a realidade. Assim entendida, a classificação revela-se mais ajustada do que se poderá pensar, porquanto acentua a factualidade incondicional do Discurso decorrente da universalidade da linguagem", cf. BERNARDO, L. Linguagem e discurso. Lisboa: INCM, 2003, p. 255.

${ }^{20}$ É sob a cifra de um retorno a Hegel que o italiano Francesco Valentini introduz o pensamento weiliano no cenário da filosofia francesa do fim dos anos de 1950. Por ser o primeiro a tomar a filosofia de Weil como objeto de interpretação e por fazê-lo à luz da sua relação com Hegel, vale retomar aqui o trecho em que Valentini estabelece as bases da sua leitura da obra weiliana: "Com Eric Weil, o retorno a Hegel assume o aspecto de um consciente retorno à razão. Mesmo se Weil não é, em sentido estreito, um polemista e apesar das evidentes diferenças de orientação filosóficas e de cultura, a sua figura, vista no quadro da cultura francesa atual, pode aproximar-se da de um [Julien] Benda, por um intransigente hábito racionalista que nada concede às tendências opostas dominantes. Mente severa, que não pensa outra coisa além de compreender, não se concede lamentos e exortações, não se pergunta se o homem é capaz de resolver os seus problemas, consideraria semelhantes questões dignas de uma razão preguiçosa, não mostraria ternura aos angustiados e às almas belas. O seu ideal humano é, em meio a tanto romantismo, aquele simples e alto do homem honesto, ligado aos seus deveres, apegado à sua profissão, do sábio que submete a paixão à razão, a sua particularidade individual a exigências mais vastas. Pensa-se espontaneamente no ideal clássico do homem razoável (ao qual Weil apela explicitamente) e, pelo outro lado, no severo costume das grandes personalidades da velha Europa, na rigidez de um Silvio Spaventa, na saúde moral de um Benedetto Croce. 'O coração tem seus direitos - escreve Weil discorrendo sobre a moral de Hegel - mas é a razão que funda esta legitimidade, a paixão é fundamental no homem, mas é a razão que constrói sobre este fundamento e que avalia as construções que se mantém neste terreno'. Submeter-se à razão significa reencontrar a autêntica liberdade e exercitá-la no quadro das instituições e dos costumes. O próprio Hegel - prossegue Weil - foi honesto: 'mesmo quem não compartilha das suas visões reconhecerá que ele jamais derrogou, que cumpriu os deveres de sua condição, que fez tudo para ser bom pai de família e bom filósofo (se a conjunção destes dois termos parece ridícula à mentalidade contemporânea, pior para esta mentalidade)"' , cf. VALENTINI, F. La filosofia francese contemporanea. Milano: Feltrinelli, 1958, p. 301-302.

${ }^{21}$ MATTOS, C. "Eric Weil - Philosophie politique". Paris: Vrin, 1956. Revista Brasileira de Filosofia 8/2 (1958), p. 267-268. Para Mattos (p. 267), “o pensamento de Eric Weil segue nas grandes linhas o hegelianismo clássico". Até onde nos é permitido saber, é este o primeiro texto sobre Weil publicado no Brasil.

${ }^{22}$ BAVARESCO, A. - COSTA, D. "Hegel e os novos rumos do espírito em Charles Taylor". In TAYLOR, C. Hegel. Sistema, estrutura e método. São Paulo: É Realizações, 2014, p. 8. 
segundo Paul Ricœur ${ }^{23}$, Weil procurou definir sua posição diante da tradição filosófica moderna. Evidentemente estamos nos referimos à expressão "kantiano pós-hegeliano"24, conhecidíssima entre os leitores de Weil. Por uma parte, o dito, em sua complexidade, parece revelar a consciência que o filósofo tem da dificuldade que o conjunto da sua obra representa para quem quiser compreendê-lo, por outra, resgata a importância da formação neokantiana de Weil.

Porquanto o "kantismo de Eric Weil" já foi bem trabalhado, por exemplo, por Patrice Canivez ${ }^{25}$, podemos nos limitar a alguns acenos. ${ }^{26}$ Nossa provocação é sublinhar que as "inspirações kantianas" constituem o núcleo do pensamento weiliano. Ao menos é a essa conclusão que nos leva a leitura de um trecho da correspondência entre os teólogos jesuítas Henry Bouillard e Henry de Lubac, mais precisamente de uma carta enviada pelo primeiro ao autor de Sur les chemins de Dieu, um dia depois da conferência de Weil, Philosophie et Réalité, em janeiro de 1963. ${ }^{27}$

Ontem à noite, na Société [Française] de Philosophie, Eric Weil expôs sua concepção da filosofia. Nada de novo para quem leu as suas diversas obras. Mas as questões que lhe foram colocadas o levaram a declarar que ele mesmo é mais kantiano do que hegeliano, que o sistema de Hegel é um fracasso, que não há e que não pode haver saber absoluto efetivamente realizado. Ao final, quando o cumprimentei, ele me confessou que é preciso coragem para dizer isso hoje em dia.

Ao fim, Bouillard expõe as próprias inquietações ironizando algumas possíveis reações de outros membros da Companhia de Jesus, sobretudo daqueles que se interessavam pela filosofia hegeliana: "Pergunto-me efetivamente se, para alguns de nós, isso não lhe levará à excomunhão... A

\footnotetext{
${ }^{23}$ RICEEUR, P. O conflito das interpretações. Porto: Rés, 1988, p. 401.

${ }^{24}$ Ricœur não apenas recorda a expressão, mas a toma por empréstimo, e acrescenta, de pronto, sua forma de apropriação: “cronologicamente, Hegel vem depois de Kant; mas nós, leitores tardios, vamos de um ao outro; em nós algo de Hegel venceu algo de Kant, mas algo de Kant venceu algo de Hegel, porque nós somos tão radicalmente pós-hegelianos como somos pós-kantianos. Na minha opinião é esta troca e esta permutação que estruturam ainda o discurso filosófico de hoje. É por isso que a tarefa é pensá-los sempre melhor, pensando-os em conjunto, um contra o outro, e um pelo outro", cf. RICEEUR, P. O conflito das interpretações, op. cit. p. 401. A expressão não aparece nos textos de Weil, mas não se contesta o seu uso por parte do autor, cf., p. e., PERINE, M. Filosofia e violência. São Paulo: Loyola, 2013, p. 125-130; JARCZYK, G. - LABARRIÈRE, P.-J. De Kojève à Hegel, op. cit. p. 180. ${ }^{25}$ Cf. CANIVEZ, P. “O kantismo de Eric Weil". Argumentos 6/11 (2014), p. 9-28.

${ }^{26}$ Não tanto para a "inspiração" kantiana no pensamento de Weil, mas propriamente para a interpretação weiliana do pensamento de Kant, cf. SALVUCCI, P. "Il Kant di Weil". In SICHIROLLO, L. (Org.). Eric Weil. Urbino: Quattro Venti, 1989, p. 99-118.

${ }^{27}$ A conferência faz parte do primeiro dos dois volumes intitulados justamente Philosophie et réalité. O livro reproduz ainda o esquema distribuído por Weil aos ouvintes e o debate que segue a apresentação, debate do qual tomam parte, entre outros, Paul Ricœur e Jean Wahl. Cf. WEIL, E. Philosophie et réaité 1. Paris: Beauchesne, 2003, p. 23-58.
} 
menos que eles não temam parecer ridículos demais, querendo sugerir que Weil não compreendeu Hegel". ${ }^{28}$

Essas considerações acerca das relações com Kant interessam sobretudo porque nos ajudam a compreender aspectos específicos da obra de Weil e logicamente da sua leitura da filosofia de Hegel.

Voltemos à história. No período do pós-guerra, Weil participa ativamente de congressos hegelianos na Alemanha, na França e na Itália. Em 1962, foi convidado por Gadamer para participar do Congresso Hegel de Heidelberg ${ }^{29}$, ocasião em que foi fundada a Internationale Hegel-Vereinigung, com o próprio Gadamer indicado para presidente e Koyré e Ritter como assessores. ${ }^{30}$ Depois, como membro da Hegel-Vereinigung, Weil ajuda a organizar o II Congresso Hegel, em Urbino, em 1965'11, e o III Congresso Hegel, em Lille, em 1968. ${ }^{32}$

${ }^{28}$ A carta de Henry Bouillard a Henry de Lubac atualmente se encontra nos arquivos dos jesuítas em Vanves, França, espera-se que a mesma apareça em breve na publicação das correspondências entre Bouillard e Weil. A esse fim trabalham, já em vias de conclusão, os professores Evanildo Costeski, da Universidade Federal do Ceará, e Michel Castro, da Université Catholique de Lille.

${ }^{29}$ Cf. Carta de Eric Weil a Livio Sichirollo, de 22 de janeiro de 1962 [disponível nos Archives Eric Weil do Institut Eric Weil, Universidade de Lille].

${ }^{30}$ Cf. BURBIDGEM, J. Historical Dictionary of Hegelian Philosophy. Lanham, Maryland: Scarecrow Press, 2008, p. XXI.

${ }^{31}$ Sobre a participação de Weil no Congresso de Urbino e a relevância de sua intervenção na renovação dos estudos hegelianos, vale a pena destacar aqui o testemunho de Raffaello Franchini: "Não se trata de uma opinião pessoal nossa, mas de uma necessidade espiritual largamente percebida [aquela de retornar a Hegel], demonstrada pelo fato de que no Congresso de Urbino, a bela conferência introdutória de um estudioso insigne como Eric Weil expunha, entre os mais sinceros consensos, ideias completamente diferentes das nossas acerca do significado e da função que assumem hoje, positivamente, a árdua retomada dos estudos hegelianos promovida pela Associação, de um lado; e, negativamente, quantos persistem em considerar supérfluo ou inatual o diálogo com a grandiosa sistematização hegeliana, de outro. Assim como em outras circunstâncias, Weil sustentou firmemente, exprimindo-se com grande clareza e lucidez, a ideia de que se manter fiel ao ensinamento de Hegel com certeza não significa transformar-se em mero repetidor do seu pensamento; mas, ao contrário, 'retomar o seu esforço, fazendo nosso o que ele pôs à nossa disposição, quer conceitos, quer problemas, a fim de que nós mesmos filosofemos sem nos perder pela estrada que ele nos indicou (...)'; assim como admiravelmente esclareceu que uma coisa é estudar Hegel com espírito crítico, outra é se iludir com a possibilidade de, deliberadamente, refutar o seu pensamento. Quem assim se ilude ou se posiciona, é, observa Weil, ao mesmo tempo um 'antifilósofo', já que todos podem se negar a compreender o que é, e a compreender, assim, a própria visão do mundo - em virtude da qual cada um se orienta na vida e no seu discurso; quem quiser pode reconhecer numa visão particular, numa preferência, numa escolha apaixonada, o essencial, e rejeitar todo o resto como mentira, erro e pecado. Em suma, todos podem rejeitar não apenas a compreensão, mas também a vontade de compreender. Neste caso, não se trata propriamente de anti-hegelianos; é-se também antiplatônico, anti-aristotélico, antifilósofo", cf. FRANCHINI, R. La logica dela filosofia. Napoli: Giannini, 1971, p. 339.

32 Em carta a Livio Sichirollo, de 09 de fevereiro de 1967 [disponível nos Archives Eric Weil do Institut Eric Weil], Weil afirma dispor de financiamento para o Congresso da Internationale Hegel-Vereinigung de Lille e propõe a Gadamer "História, Política, Arte, Religião e Filosofia em Hegel" como tema central do Congresso. 
Porém, no que tange ao nosso tema, temos de reconhecer não só os motivos históricos da ligação de Weil com a filosofia hegeliana, mas, mais propriamente, as suas razões sistemáticas, isto é, filosóficas. Com efeito, se por um lado a presença de Hegel no pensamento weiliano é indiscutível, por outro, ela pode ser tomada em perspectivas distintas. Em todas elas, porém, o autor da Filosofia do direito aparece como "grande interlocutor filosófico de Weil" ${ }^{33}$, assumindo o papel de uma "presença fundadora". ${ }^{34}$ Nosso objetivo imediato é rever essa presença à luz da leitura weiliana de algumas reações ao pensamento hegeliano na filosofia francesa contemporânea. Esperamos que esse expediente destaque elementos que resgatem a filosofia weiliana das leituras que o consideram como mero intérprete de Hegel, justamente por salientar a sua originalidade tanto no que respeita ao seu liame com o mestre de Berlin quanto às suas relações com o cenário da filosofia francesa do seu tempo.

\section{O juizo weiliano sobre as tentativas francesas de superação da filosofía hegeliana}

O termo que escolhemos, "pós-hegeliano", pode ser tomado sob duas acepções fundamentais e distintas. Em uma, ele significa simplesmente, na história do pensamento, aquilo que se desenvolve depois, cronologicamente, da obra de Hegel. Em outra, a que de fato nos interessa agora, compreende as diferentes reações ao ideal moderno de "pensamento puro" e muito particularmente ao pensamento hegeliano como figura definitiva desse mesmo ideal. São essas reações que, na abordagem de Georg Sans, por exemplo, formam "a encruzilhada da filosofia contemporânea". Para Sans, a grande variedade e a fragmentação das propostas filosóficas do fim do século XIX e de todo o século XX podem ser entendidas como resultado das diferentes tentativas de resposta aos grandes sistemas do pensamento idealista. Logo, porquanto temos nele o sistema mais completo e particularizado,

não é exagero dizer que a oposição a Hegel condicionou os debates filosóficos dos séculos XIX e XX, a tal ponto que também quem tinha a pretensão de estar nos antípodas de qualquer sistema idealista, tenha sido significativamente influenciado por ele. Hoje, as opiniões sobre Hegel divergem, e é exatamente por isso que as grandes correntes filosóficas contemporâneas se apresentam como uma série de contrapropostas à ideia de um pensamento puro. ${ }^{35}$

\footnotetext{
${ }^{33}$ PERINE, M. Filosofia e violência, op. cit. p. 115.

${ }^{34}$ KIRSCHER, G. Figures de la violence et de la modernité. Lille : Presses Universitaires de Lille, 1992, p. 234. A expressão é tomada também por Pierre-Jean Labarrière, cf. JARCZYK, G. - LABARRIÈRE, P.-J. De Kojève à Hegel, op. cit. p. 181.

${ }^{35}$ SANS, G. Al crocevia della filosofia contemporanea. Roma: Gregorian \& Biblical Press, 2012, p. 15.
} 
Weil parece compartilhar essa leitura quando nota entre os filósofos contemporâneos "uma vontade evidente de saber o que os mestres disseram e quiseram dizer" ${ }^{36}$, reconhecendo não só em Hegel, mas também em Aristóteles e Nietzsche, aqueles que na metade do século passado suscitavam um maior entusiasmo em filosofia.

O pós-hegelianismo de Eric Weil nos orienta em duas direções diferentes. Por um lado, devemos considerar a posição do filósofo diante das correntes da filosofia contemporânea, por outro, delinear como Weil verdadeiramente se põe diante dos dilemas das filosofias pós-hegelianas na França. Evidentemente a compreensão das questões postas exigiria de nós o trabalho com o conjunto completo da obra weiliana, entretanto aqui prestigiamos a leitura de textos específicos, esperando que sejam, ao final, suficientes para sustentar as nossas hipóteses. No que concerne à leitura weiliana de algumas correntes filosóficas contemporâneas na França, trabalharemos precisamente - mas não exclusivamente - os textos "The strength and weakness of existentialism", de 1952; "Philosophical and political thought in Europe today", de 1964; bem como as recensões "À propôs du matérialisme dialectique" e "Marx et la liberte", de 1946 e 1947, respectivamente. Tomamos ainda algumas cartas de Eric Weil a Georges Bataille, sobretudo uma de 26 de junho de 1946, na qual o autor comenta os livros de Ferdinand Alquié e de Jean-Paul Sartre sobre o marxismo. Nesses textos, Weil aborda diretamente parte do contexto filosófico francês do século passado, elencando inclusive, ao lado de autores bastante presentes na sua obra, nomes que não aparecem com tanta frequência em sua obra. ${ }^{37}$ Nesses escritos, entre recensões, artigos e correspondências, podemos verificar finalmente como Eric Weil analisa as reações ao projeto hegeliano a partir das suas críticas a dois eixos fundamentais da filosofia francesa contemporânea: em primeiro lugar, o existencialismo, depois a recepção na França do pensamento de Marx.. ${ }^{38}$

No seu primeiro momento, nossa tarefa de certa forma retoma e aplica ao pensamento de Eric Weil o que é posto por Jean Quillien. Primeiramente, que toda filosofia "traduz algo da realidade que constitui seu material e seu ponto de partida", ${ }^{39}$ mas, sobretudo, que "uma filosofia se forja num confronto com outros pensamentos, e se oferece como o resultado, que

\footnotetext{
${ }^{36}$ WEIL, E. Essais sur la philosophie, la démocratie et l'éducation. Lille: Presses Universitaires de Lille, 1993, p. 85.

${ }^{37}$ Com efeito, ali estão, ao lado de Wittgenstein, os nomes de Austin e Ayer, e da mesma forma, com Heidegger, comparecem Freud, Camus, Sartre, Marcel e Merleau-Ponty.

${ }^{38}$ Sobre essas passagens nas categorias que superam o "Absoluto" na Logique de la philosophie, cf. RICEEUR, P. De l'Absolu à la Sagesse par l'Action. In Actualité d'Eric Weil. Paris: Beauchesne, 1984, p. 407-423 e PARASILITI, S. Le categorie post-hegeliane nella Logique de la philosophie. In SICHIROLLO, L. (Org.). Eric Weil. Urbino: QuattroVenti, 1989, p. 59-98.

${ }^{39}$ QUILLIEN, J. "Eric Weil et notre temps". In QUILLIEN, J. - KIRSCHER, G. (Edd). Cahiers Eric Weil IV. Septentrion: Villeneuve d'Ascq, 1996, p. 39.
} 
com frequência quer ser radicalmente novo, de toda uma tradição filosófica, ao mesmo tempo em que se situa em relação às outras correntes de pensamento que visam dizer a mesma realidade" ${ }^{40}$ É absolutamente coerente, portanto, procurar na obra weiliana o seu modo próprio de pensar a filosofia do seu tempo, situando-se, assim, entre as diferentes correntes filosóficas que se dão como "tradução pensada do mundo na segunda metade do século XX".

Duas últimas observações são imprescindíveis. Antes de tudo, sublinhamos, agora de forma explícita, que o nosso interesse se restringe exclusivamente à leitura weiliana de distintos aspectos da filosofia francesa contemporânea e não a uma apresentação exaustiva de algum deles. Por último, não seguimos uma ordem histórica, mas lógica, começando com a leitura weiliana do existencialismo para concluir com as suas considerações sobre algumas interpretações francesas de Marx, através de quem Hegel age em nossa época. ${ }^{41}$

\subsection{A força e a fraqueza do existencialismo}

A abordagem weiliana do existencialismo ${ }^{42}$ traz ao menos duas marcas fundamentais: de um lado, toma seriamente o fato de que a nossa situação filosófica atual só pode ser compreendida se considerarmos (...) o existencialismo" 43 , e, de outro, a opção do autor de privilegiar em suas análises a versão francesa desse discurso. No que concerne a esse segundo aspecto, reconhecemos duas razões para Weil se limitar ao existencialismo francês. Antes de tudo, há um motivo meramente editorial, quer dizer, o fato de que o filósofo trata do tema no contexto de uma apresentação da filosofia francesa à revista estadunidense The Listener. Depois, porque diferentemente da Alemanha, onde o existencialismo se restringiu às universidades, na França ele se pôs no "centro do pensamento", entendido aqui também como "sensibilidade de uma geração" 44 , facilmente reconhecível no sucesso de sua influência na política e na literatura e na celebrização de nomes como os de Jean-Paul Sartre e de Gabriel Marcel.

O seu ponto de partida aponta para a dificuldade de definir o existencialismo, afirmando precisamente que "há tantas definições [para o

\footnotetext{
${ }^{40}$ QUILLIEN, J. "Eric Weil et notre temps", op. cit. p. 39-40.

${ }^{41}$ Cf. WEIL, E. Hegel et l'Etat. Paris: Vrin, 2002, p. 105.

${ }^{42}$ Para a crítica de Weil ao existencialismo considerando também o discurso desenvolvido na categoria do "Finito" na Logique de la philosophie, cf. BERNARDO, L. Liberdade ou satisfação: a crítica de Eric Weil ao existencialismo. In REIMÃO, C. (Org.). Jean-Paul Sartre, uma cultura da alteridade: filosofia e literatura. Universidade Nova de Lisboa, 2005, p. 277-290.

${ }^{43}$ WEIL, E. Essais et conférences 1. Paris: Vrin, 1991, p. 264.

${ }^{44}$ WEIL, E. Essais sur la philosophie, la démocratie et l'éducation, op. cit. p. 93
} 
existencialismo] quanto existencialistas" ${ }^{45}$ Desse modo, podemos dizer que o texto de 1952, importa recordar o título, "The strength and weakness of existentialism", orbita justamente ao redor da questão: "o que é o existencialismo?". ${ }^{46} \mathrm{O}$ caminho é aquele peculiar ao autor, ou seja, a retomada crítica, em níveis diferentes, das respostas disponíveis, indicando seus limites e suas imprecisões.

De modo geral, o existencialismo pode ser tomado como "uma forma de pensar que exige que a razão exiba seus títulos e suas credenciais" ${ }^{47}$ Logo, um discurso que põe a razão em questão; está justamente aí o problema, primeiro discernir que a crítica se dirige à razão abstrata, depois que esta deve ser agora considerada naquilo que tem de insuficiente diante dos problemas e dos sofrimentos do indivíduo. O quadro referencial que sustenta a estrutura desse discurso deve necessariamente ser interpretado como uma forma de reação a Hegel, pois, em última instância, e Weil o diz de modo explícito, trata-se sempre, fundamentalmente, dos ecos da recusa de Kierkegaard à dialética hegeliana não só na insistência no mistério e no escândalo da fé, mas sobretudo na criação de uma situação na qual "a dialética objetiva da relação sujeito-objeto de Hegel se torna um dos polos de uma oposição da qual o indivíduo, na sua subjetividade irredutível, constitui o outro". ${ }^{48}$ Em suma, no existencialismo, o que está em questão é precisamente a razão abstrata, o entendimento, a Verstand, incapaz de tomar o indivíduo como o que este é na sua verdade, ser que não tem outros problemas e outros sofrimentos além daqueles que lhe são próprios. ${ }^{49}$

A partir desse primeiro esboço de definição, Weil retoma o tema sob três diferentes perspectivas. Nas duas primeiras, fiel ao título do artigo, aponta respectivamente para a força e para a fraqueza do discurso existencialista; na última, na forma de conclusão, se posiciona introduzindo inclusive algumas das suas reservas diante do existencialismo heideggeriano. ${ }^{50}$

Em poucas palavras, a potência do existencialismo é ter retornado à questão fundamental sobre o homem dentro da crise da civilização ocidental, fazendo-se ele próprio uma expressão dessa crise. O homem é tomado, independentemente da forma de se considerar o problema, como indivíduo que não se pode simplesmente identificar com a razão, pois "não vive num universo de conceitos e de abstrações científicas; ele é vida e sentimento,

\footnotetext{
45 Idem, p. 93

46 Idem, p. 93

47 Idem, p. 93-94.

${ }^{48}$ WEIL, E. Philosophie et réaité 1, op. cit. p. 264.

49 WEIL, E. Essais sur la philosophie, la démocratie et l'éducation, op. cit. p. 94.

${ }^{50}$ Ver o artigo "Le cas Heidegger", in WEIL, E. Philosophie et réalité 2. Paris : Beauchesne, 2003, p. 255-266.

${ }^{51}$ WEIL, E. Essais sur la philosopie, la démocratie et l'éducation, op. cit. p. 98.
} 
e não uma entidade psicológica, uma máquina ou um modelo mecânico feito de matéria imaterial, é ele mesmo e não uma coisa, qualquer que seja a maneira de se definir uma coisa" ${ }^{51}$ As preocupações do existencialismo são legítimas, Weil não vê problema em admitir, pois "a razão levou à violência, e a ciência à crise econômica, à revolução, à destruição" ${ }^{52} \mathrm{O}$ existencialismo critica, então, o pensar que negligencia aquelas preocupações antigas, fundamentais, de todo ser humano, inclusive do filósofo.

No entanto, porquanto quer ser científico, o existencialismo levanta afirmações pretensamente válidas para todo ser razoável, dito de outro modo, ele quer ser verdadeiro no sentido pleno do termo. Desse modo, finda por se colocar diante de uma ubiquidade sem solução: ou a generalidade na qual não se pode dizer "eu", mas apenas personalidade e existência, nem história ou tempo, mas historicidade e temporalidade ${ }^{53}$; ou a poesia, para alguns pensadores existencialistas, mais poderosa e verdadeira que a filosofia tradicional.

Para Weil, a possibilidade de uma saída aparece justamente na contradição levantada, pois, admitindo-se que "o pensamento abstrato não é necessariamente um pensamento que se ocupa de objetos abstratos" ${ }^{\prime \prime 4}$, seria então possível protestar contra uma filosofia que concede a preeminência à razão formal e aos objetos abstratos, e ao mesmo tempo quer respeitar as exigências da filosofia científica.

\subsection{Marx e a liberdade: a crítica de Weil a Sartre, Alquié e Étiemble}

A outra reação a Hegel, certamente muito mais presente na reflexão weiliana que os temas existencialistas, é a obra de Marx. Aqui a questão fundamental é pensar a legitimidade da passagem própria ao pensamento marxiano da filosofia à ciência e à técnica ${ }^{55}$, ou seja, se se pode, de fato, transformar em conceitos científicos e fatores revolucionários os elementos do pensamento hegeliano, o que Marx faz ao aplicar o "conceito de negatividade, tal como desenvolvido na Fenomenologia, aos dados estruturais elaboradas na Filosofia do Direito". ${ }^{56}$ Para Weil, "Hegel provavelmente não teria aprovado a ciência de Marx, que, no entanto, foi na história uma das traduções da filosofia de Hegel" ${ }^{57}$

\footnotetext{
${ }^{52}$ Idem, p. 100.

53 “Ele não pode dizer 'eu', ou pelo menos ele não pode tomar essa palavra 'eu' no sentido mais estrito, aquele no qual ele significa eu, que nesse momento falo", cf. WEIL, E. Essais sur la philosophie, la démocratie et l'éducation, op. cit. p. 100.

${ }^{54}$ WEIL, E. Essais sur la philosophie, la démocratie et l'éducation, op. cit. p. 101.

${ }^{55}$ Cf. WEIL, E. Hegel et l'Etat, op. cit. p. 114-115.

${ }^{56}$ Idem, p. 109.

${ }^{57}$ Idem, p. 115-116.
} 
Sobre as dificuldades nos debates acerca do pensamento de Marx, Weil descreve o cenário com uma imagem de guerra. "De um lado da barricada, prostra-se diante do fundador, venerado a ponto de não se ousar erguer os olhos diante dele; de outro, entra-se em transe tão logo se pronuncie o nome abominável". ${ }^{58}$ Nós abordaremos o tema a partir de textos nos quais Weil trata diretamente do problema, a saber, duas recensões da revista Critique, o texto "Marx et la philosophie du droit", depois anexado em Hegel et l'État, e, finalmente, as cartas de Weil a Bataille, em fevereiro e em junho de 1946. O valor destas últimas, especialmente a de 26 de junho, é imenso para a nossa reflexão porquanto nela Weil dirige suas críticas a Ferdinand Alquié e a Jean-Paul Sartre, autores respectivamente de $M a$ térialisme ou cartésianisme ${ }^{59}$ e Matérialisme et révolution ${ }^{60}$, ao mesmo tempo em que destaca os limites e os equívocos dos que ele mesmo chama de marxistas ortodoxos.

De modo geral, a leitura das cartas a Bataille nos mostra um Weil que "se exprime como filósofo especialista em filosofia política, em particular na filosofia de Hegel e de Marx e nas relações entre Hegel e Marx". ${ }^{61}$ De fato, a carta de 01 de fevereiro de 46 apresenta as reações pessoais e apaixonadas por trás da recensão "À propôs du matérialisme dialectique", sobre o escrito de René Étiemble, "Dialectique matérialiste et dialectique taoiste". ${ }^{62}$ Se no texto da recensão de Weil o tom é marcado pela ironia, a missiva impressiona pela exasperação: "Étiemble me enfureceu de tal forma que redigi uma nota (...). Não sei onde publicá-la. Mas tive que colocar para fora: a mistura de banalidade, pretensão e ignorância me foi insuportável". ${ }^{63}$

Quanto a Alquié e Sartre, Weil inicia reconhecendo que ambos "parecem ter razão contra os '[marxistas] ortodoxos"', e continua, "eu iria ainda mais longe: fazem um trabalho muito útil apontando para esses senhores a insuficiência de sua posição no plano filosófico". ${ }^{64}$ No entanto, não os poupa de críticas, "pois sua própria posição é insuficiente: a filosofia da

\footnotetext{
${ }^{58}$ WEIL, E. “Marx et la liberte André Vène, Vie et doctrine de Karl Marx". Critique 2 (1947), p. 69.

${ }^{59}$ Cf. ALQUIÉ, F. Matérialisme ou cartésianisme. Les Temps Modernes 8 (1946), p. 1378-1400.

${ }^{60}$ Cf. SARTRE, J.-P. Matérialisme et révolution I. Le mythe révolutionnaire. Les Temps Modernes 9 (1946), p. 1537-1563; ID. Matérialisme et révolution II. Les Temps Modernes 10 (1946), p. 1-32.

${ }^{61}$ PATRON, S. "Préface". In BATAILLE, G.; WEIL, E. À en-tête de Critique. Correspondance, 1946-1951. Paris: Lignes, 2014, p. 18.

${ }^{62}$ ETIEMBLE, R. Dialectique matérialiste et dialectique taoiste L'Arche 11 (1945), p. 62-82.

${ }^{63}$ BATAILLE, G.; WEIL, E. À en-tête de Critique. Correspondance, 1946-1951. Paris: Lignes, 2014, p. 54

${ }^{64}$ BATAILLE, G.; WEIL, E. À en-tête de Critique, op. cit. p. 68. “Marx é um grande assunto, porque há marxistas, e os marxistas são homens de ação. É um elemento primordial e ainda assim não é suficiente: é insuficiente quando não se trata de luta, mas de compreensão; especialmente no ponto em que a ação se afirma razoável e apreende sua essência nesse caráter", cf. WEIL, E. "Marx et la liberte André Vène, Vie et doctrine de Karl Marx", op. cit. p. 70.
} 
reflexão de Alquié se endereça de fato contra aquela de Hegel" ${ }^{\prime 65}$, enquanto a concepção sartriana da revolução, porquanto abstrata e a-histórica, é absolutamente inconciliável com o marxismo. Com efeito, sempre segundo a interpretação weiliana, a revolução em Sartre se põe como "ato arbitrário (...) a tal ponto que a partir dele, o super-homem de Nietzsche seria um fim revolucionário tanto quanto a salvação budista ou a sociedade sem classes" ${ }^{66}$

Porém, há uma crítica que Weil dirige a uma só vez a Alquié, a Sartre e aos representantes do marxismo oficial, a saber, que todos eles confundem filosofia com a realização da filosofia. É a partir dessa distinção que podemos também compreender a posição de Weil frente à reação de Marx ao projeto hegeliano. Para Weil, é essencial compreender que "Marx não quis ser um filósofo, mas realizar uma filosofia que ele aceitou" ${ }^{67} \mathrm{O}$ que fica entendido aqui é que, em Weil, os termos "realizar", "realização" e mesmo "supressão da filosofia", resumem a passagem da filosofia à ciência, do idealismo da filosofia a uma ciência materialista e dialética da sociedade. A consequência disso é que as proposições dessa ciência podem ser apreendidas em termos de veracidade e de falsidade, logo, é possível considerar que elas se tornem falsas por alguma ação autofalsificadora, porque na origem elas foram verdadeiras. Em tudo isso, porém, Marx continua em acordo com Hegel, de tal modo que, em sua opinião, a filosofia hegeliana é a última filosofia. Contudo, "ela era apenas uma filosofia, era ainda preciso realizar o seu conteúdo" ${ }^{68}$ Dito de outra forma, "eles não compreenderam que a filosofia só compreende a ação concreta, mas não pode dirigi-la enquanto filosofia", ou seja, "não compreendem a diferença essencial entre teoria e práxis". ${ }^{69}$

Em 1947, em "Marx et la liberté" Weil volta novamente ao pensamento de Marx, desta vez na leitura de Vie et doctrine de Karl Marx, de André Vène, autor que, segundo a interpretação weiliana, "não compreendeu uma única palavra de Hegel nem o lugar que Marx reserva àquele que foi aos seus olhos o último filósofo" ${ }^{70}$ De fato, nessa recensão, Weil retoma a distinção fundamental entre teoria e práxis, salientando mais uma vez a importância da compreensão do problema capital do pensamento marxiano: "uma só coisa importa a Marx, e é a liberdade do homem. Tudo decorre desse único problema"71 - o que será reforçado adiante

\footnotetext{
${ }^{65}$ BATAILLE, G.; WEIL, E. À en-tête de Critique, op. cit. p. 68.

${ }^{66}$ Idem, p. 69.

${ }^{67}$ Idem, p. 69.

${ }^{68}$ WEIL, E. À propos du matérialisme dialectique. Etiemble, Dialectique materialiste et Dialectique taoiste. Critique 1 (1946) p. 87-88)

${ }^{69}$ BATAILLE, G.; WEIL, E. À en-tête de Critique, op.cit. p. 69.

${ }^{70}$ Ibid.

${ }^{71}$ WEIL, E. Marx et la liberte André Vène, Vie et doctrine de Karl Marx, op.cit. p. 71.
} 
ao afirmar que "a liberdade é o problema essencial em relação ao qual as outras questões se situam"..$^{72}$ No entanto, tudo isso só pode ser bem entendido se mantivermos vivo o fato de que Marx "não queria compreender a liberdade, mas realizá-la". ${ }^{73}$

O problema pode finalmente ganhar contornos mais precisos, pois se por um lado, o homem é livre, por outro, na nossa sociedade, essa liberdade existe negada pelas condições: para que o homem se torne o que é, é preciso que se faça senhor das condições, que são criação sua, criação em favor da qual ele se alienou de tal forma que não reconhece sua obra como sua e se encontra determinado por ela. Ele deve transformar essas condições no terreno da realidade e não apenas no domínio do pensamento, dito de outro modo, ele deve se tornar livre, não somente se compreender como tal.

Marx entende a liberdade nos moldes hegelianos para a negatividade do homem, quer dizer, a possibilidade de superar o dado, inclusive o dado que é o próprio homem nas suas realizações concretas, históricas. Mas se separa do mestre de Berlim quando este se contenta com a compreensão da história e com o devir da consciência da liberdade. Para Marx, o homem só se sabe senhor da condição ao vencê-la no plano da própria condição. Caso contrário, abandona-se a uma ideologia na qual o indivíduo satisfeito é tomado como homem tout court, ideologia na qual ainda uma parte da sociedade pensa ter alcançado o fim da história, um estado de coisas invariável, esquecendo-se de que "os processos não param jamais e a ciência formal do movimento (Hegel) não introduz na eternidade, ainda que seja sempre verdadeira - justamente porque é apenas formal" ${ }^{74}$

O que ocupa Marx, e jamais deixou de preocupá-lo, é a questão da liberdade do homem no mundo, e para ele o homem não é livre justamente porque há homens que se tornam coisas da existência. Em última instância, podemos concluir com Weil

A grandeza de Marx foi ver que o homem sofre sob a lei das coisas e que, contudo, essa lei continua uma obra sua. Se ele quer se libertar, não conseguirá com a ajuda de desejos piedosos; a lei - que não é nada além do que a forma concreta na qual a negatividade humana se impõe ao dado da natureza - é uma lei histórica, quer dizer, humana, e que contém nela mesma aquela negatividade pela qual deve se transformar. Ela é necessária, porque o homem criou um domínio da negatividade; ela é histórica, porque o homem continua negatividade mesmo nesse domínio da necessidade. ${ }^{75}$

${ }^{72}$ Idem, p. 72.

${ }^{73}$ Idem, p. 71.

${ }^{74}$ Idem, p. 73.

${ }^{75}$ Idem, p. 74. 


\subsection{Eric Weil: o sentido da filosofia diante do evangelho da violência pura}

À diferença dessas duas distintas reações ao projeto hegeliano na França, Weil escolhe responder ao mestre de Berlim mantendo-se nos domínios do discurso filosófico. À base de sua posição está, então, um espírito crítico capaz de evitar a um só tempo a superfluidade da mera repetição do pensamento de Hegel e a ilusão de uma total rejeição do Absoluto no terreno discursivo. Há de se sublinhar fortemente que essa rejeição é ilusória só e exclusivamente no plano filosófico no qual a radical refutação do projeto hegeliano não se faz sem a completa negação da compreensão, da vontade de compreender, quer dizer, sem se fazer ela mesma uma posição - como Weil esclarece em Urbino, em 1965 - não apenas anti-hegeliana, mas também antiplatônica, anti-aristotélica e ao fim e ao cabo fundamentalmente antifilosófica.

Para Weil, se pode haver algum "hegelianismo" depois de Hegel, ele só será coerente se levar em conta não apenas essa possibilidade de rejeição do discurso e da razão, mas a sua efetiva realização histórica. Definitivamente, a filosofia pós-hegeliana, e está aqui, sabidamente, o imo da filosofia weiliana, vê-se lançada numa renovada "crise de confiança" aprofundada justamente pelo fenômeno contemporâneo do anúncio do "evangelho da pureza da violência". ${ }^{76}$ Não há quem duvide do papel da violência para a construção dos argumentos de Weil, no entanto, parece-nos válido remeter a um testemunho insuspeito de como ela assume o lugar de centro; é o que Livio Sichirollo faz ao retomar as palavras que Weil teria dito a Massimo Barale: "Acontece, em filosofia, que os mestres involuntários ensinem mais do que tantos mestres voluntariosos. Meu mestre involuntário foi Adolf Hitler" ${ }^{77}$ Tratando-se deste mestre só se pode aprender uma única lição. ${ }^{78}$ Weil então não pode não pensar o fato da violência, entendida no conjunto de sua obra sob registros diferentes e tão difícil de apreender quanto nos é difícil a apreensão da própria razão. ${ }^{79}$ No entanto, naquilo que a história

\footnotetext{
${ }^{76}$ WEIL, E. L'avenir de la philosophie, op. cit. p. 16.

${ }_{77}$ SICHIROLLO, L. La dialettica degli antichi e dei moderni, op. cit. p. 32.

${ }^{78}$ Com efeito, Weil encontra na linguagem do movimento totalitário, evidentemente no nazismo, a tradução histórica da recusa de todo discurso coerente. A lição aprendida é, portanto, a descoberta desta possibilidade, e o filósofo a ilustra com um pequeno relato: "Um chefe da SS declarou um dia numa reunião pública: 'Quando eu ouço a palavra cultura, saco meu revólver'", cf. WEIL, E. Philosophie et réaité 2. Paris: Beauchesne, 2003, p. 8. A mesma imagem se encontra no início da Logique: "o pensamento deve estar bem avançado para que alguém possa declarar que saca seu revólver assim que ouve a palavra 'civilização'", cf. WEIL, Logique de la philosophie, op. cit. p. 60, e essa repetição nos obriga a tomá-la seriamente.

${ }^{79}$ Luís Manuel Bernardo faz um inventário das formas como a violência aparece na obra weiliana: "Em Weil, tendo em vista as exigências, são considerados três grandes níveis de violência: 1 . a violência da vida, isto é, de atitudes; 2 . a violência do discurso, ou seja, de categorias, como estabelecer o significado de certa atitude e justificar tal concepção da vida como sendo a melhor, e 3. a violência do mal desejado. Deve-se notar que este terceiro nível
} 
recente nos deu de novo e que Hegel não poderia pensar em toda a sua extensão, essa violência se mostrou na sua pureza nas experiências totalitárias, de um lado, e, de outro, na insatisfação do indivíduo moderno, quer dizer, no "tédio do progresso infinito e insensato" 80 , "produzido pela insatisfação de um interesse satisfeito", fruto da desnaturalização do tempo livre em esvaziamento dedicado à diversão viciosa, que faz da violência gratuita "o único passatempo verdadeiro". ${ }^{81}$

O que se deve considerar é a recusa do filosofar tout court. A aporia se põe aqui na sua máxima radicalidade, pois se Hegel é a figura ideal do discurso absolutamente coerente ${ }^{82}$, é diante do seu pensamento que se tornam mais patentes as consequências da linguagem segundo a qual "toda coerência é falsa coerência". ${ }^{83}$ A recusa, portanto, é completa e, modernamente original, com conhecimento de causa, é a própria filosofia que é posta em questão, quer dizer, não se trata mais de um ataque visando "uma tal filosofia em nome da filosofia, [esse ataque] não se inspira pela vontade de filosofar" ${ }^{84}$

\section{Considerações finais}

Enfim, como considerações finais, mas sem nenhuma pretensão de exaurir as questões levantadas, gostaríamos simplesmente de retomar algumas noções essenciais da natureza e da tarefa da filosofia segundo Eric Weil, noções diante das quais, até onde conseguimos perceber, Hegel manteria algumas reservas.

Antes de tudo, para Eric Weil, a filosofia pode hoje ser tomada como o esforço de quem, sem poder abrir mão daquilo que o discurso absolu-

\footnotetext{
não pode ser entendido sem referências aos outros dois, pois faz uso daqueles e se volta para eles, o que, novamente, pede uma abordagem dialética e hermenêutica para a ação em particular. A fim de melhor exercer esse ponto, vamos também colocar as quatro figuras antropológicas da violência estabelecidas pelo autor sobre a violência da vida: 1 . Violência de quem não aceita o outro do discurso, 2. Violência de quem está aferrado à sua própria identidade e não quer ouvir nem se expressar; 3 . Violência que resulta da convicção de que o que é importante na vida humana não vem de decisões e ações humanas, mas de algum efeito natural ou da deliberação de alguma autoridade suprema; 4 . Violência daqueles que não acham possível entregar-se em determinadas circunstâncias. Em todas essas quatro situações está sempre em jogo uma certa maneira de lidar com o discurso ou com a atitude, ou com ambos", cf. BERNARDO, L. Reasons of violence. Violence of reason: an interpretation based on Eric Weil's core paradox. In: AURÉLIO, D. P. and PROENÇA, J. (Org.). Terrorism: Politics, Religion, Literature. Cambridge: Cambridge Scholars Publishing, 2011, p. 47.

${ }^{80}$ WEIL, E. Violence et langage. In QUILLIEN, J. (Org.), Cahiers Eric Weil I. Lille: Presses Universitaires de Lille, 1987, p. 29.

${ }^{81}$ WEIL, E. Philosohie et ráelité 1, op. cit. p. 303.

${ }^{82}$ Cf. WEIL, E. Logique de la philosophie, op. cit. p. 51.

${ }^{83}$ WEIL, E. L'avenir de la philosophie, op. cit. p. 15.

${ }^{84}$ Idem, p. 11-12.
} 
tamente coerente revelou, se vê imediatamente diante de um mundo no qual a busca de sentido não se mostra como a primeira atitude realizada. Podemos avançar na questão deixando de lado uma ideia vaga de filosofia e tomá-la, com Weil, como "ciência do sentido" 85 e "esforço em direção do sentido" ${ }^{86}$ Logo, ela se identifica constitutivamente com o filósofo, pois - é ao mesmo tempo banal e fundamental afirmar - "não existe filosofia sem filósofos" ${ }^{\prime 77}, \log$, há filosofia porque há quem livremente escolhe compreender a textura da realidade, isto é, esforçar-se para "prender juntas as contradições na unidade de um sentido" .88

A descoberta pós-hegeliana de que, com conhecimento de causa, "é sempre possível refutar a questão do sentido", recoloca no centro dos nossos quadros teóricos contemporâneos o sentido da questão, isto é, exige-se repensar as condições de possibilidade da escolha da filosofia. Não foi por acaso que as justificativas da filosofia ganharam um capítulo tão vigoroso na segunda metade do século passado. No concernente a esse tema, Weil não se limita a assumir a compreensão da filosofia como um esforço sempre in fieri e jamais plenamente rebatado, antes sustenta nesse domínio uma postura absolutamente particular: a filosofia é injustificável.

Em segundo lugar, ela se faz fundamentalmente como passagem da certeza à discussão. Dito de outro modo, exige a desinstalação de qualquer perspectiva ideológica na direção da compreensão do sentido. Essa passagem é essencialmente anti-ideológica justamente porque o esforço da compreensão problematiza também o ponto de vista de quem quer compreender, isto é, deve pôr sempre em questão também os limites da perspectiva adotada pelo próprio filósofo. Daqui, decorrem duas consequências inevitáveis. Primeiramente, o fato de que essa escolha não se concilia absolutamente com generalizações abstratas ou com propostas pretensamente neutras ou indiferentes. Weil é incisivo e as inúmeras repetições disso na Introdução da Logique não deixam dúvidas, a filosofia é só uma possibilidade, mas uma vez realizada, a sua escolha engaja o filósofo, que tanto deve guardar o "segredo" 89 de que o escopo definitivo da sua ação é essencialmente o fim da violência, quanto lidar com o medo de que a violência hoje refutada seja amanhã o seu destino. ${ }^{90} \mathrm{~A}$ decisão é sempre precária e sem garantias de sucesso e exige a cada instante a resposta animada pela "coragem da razão".

\footnotetext{
${ }^{85}$ WEIL, E. Logique de la philosophie, op. cit. p. 420.

${ }^{86}$ WEIL, E. Violence et langage, op. cit. p. 31.

${ }^{87}$ WEIL, E. L'avenir de la philosophie, op. cit. p. 9.

${ }^{88}$ WEIL, E. Logique de la philosophie, op. cit. p. 425.

${ }^{89}$ WEIL, E. Logique de la philosophie, op. cit. p. 20.

${ }^{90}$ Idem, p. 19.
} 
Essa tarefa não é indiferente, e isso muito simplesmente porque "ninguém gosta do desconforto da insegurança", da falta de certeza. Boa parte da dinâmica da Introdução da Logique de la philosophie se desenvolve precisamente ao redor do fato de que o filósofo não vive imerso na presença do sentido nem dispõe de um mundo imediato e inteiramente sensato, mas compartilha o "mundo da vida" com o "homem comum", com o "poeta", com o "homem da ciência", com aqueles que comumente podem protestar - e efetivamente protestam - contra a filosofia, quer porque "possuem evidências e, particularmente, evidências científicas" quer porque, aos seus olhos, se não impossível, a filosofia é inútil, pois “engana os espíritos e os fecha a outras formas de saber, mais sólidas, mais salutares e mais úteis" ${ }^{92}$

A rejeição do filósofo tornou-se um fato desde que Sócrates trouxe a filosofia do céu para a terra. Os ataques que sofreram e que sofremos, nós que escolhemos compreender, são parte constitutiva do ofício daqueles que Weil chama sempre de "homens de cultura" ou "homens de diálogo". ${ }^{93}$ Mas paradoxalmente esse contexto é ele mesmo uma condição da nossa esperança. Como salienta em 1974, numa conferência a professores de filosofia em Nice, e é urgente que estas palavras ecoem aqui, "a filosofia, é preciso confessá-lo, prospera durante as épocas que, com certeza, não são aquelas do silêncio, da extrema miséria, mas que não são igualmente aquelas do conforto intelectual e da tranquilidade social, política, moral: nesse sentido, não é improvável que a filosofia tenha hoje um belo futuro pela frente". ${ }^{94}$

A última consequência da escolha pela filosofia tem a ver com a compreensão de que o sentido não há de ser simplesmente apreendido no devir da história, nem mesmo contemplado nos supostos eventos prolépticos da sua presença. Antes, deve se realizar em quem o busca de forma consciente e que orienta por essa busca a sua ação, a isso chamamos moral, bem como deve se tornar presente no mundo no qual esse mesmo sentido possa ser buscado, e a essa realização chamamos política. Logo, não são somente as condições para a compreensão do sentido que estão em jogo, mas, sobretudo pelo seu primado problemático, as condições de possibilidade para a sua realização numa vida sensata. Por isso, na história pós-hegeliana, pensar a moral, a política e a educação são tarefas incontornáveis de toda filosofia digna desse nome.

${ }^{91}$ WEIL, E. L'avenir de la philosophie, op. cit. p. 12.

${ }^{92}$ Idem, p. 12.

${ }^{93}$ Cf. WEIL, E. Philosophie et réalité 2, op. cit. p. 3-12.

${ }^{94}$ WEIL, E. L'avenir de la philosophie, op. cit. p. 21. 


\section{Referências}

ALQUIÉ, F. Matérialisme ou cartésianisme. Les Temps Modernes 8 (1946), p. 1378-1400. BADIOU, A. Panorama de la philosophie française contemporaine. Eikasia Revista de Filosofia 3 (2006), p. 1-14.

BATAILlE, G. - WEIL, E. À en-tête de Critique. Correspondance, 1946-1951. Paris: Lignes, 2014.

BAVARESCO, A. - COSTA, D. Hegel e os novos rumos do espírito em Charles Taylor. In TAYLOR, C. Hegel. Sistema, estrutura e método. São Paulo: É Realizações, 2014.

BERNARDO, L. Liberdade ou satisfação: a crítica de Eric Weil ao existencialismo. In REIMÃO, C. (Org.). Jean-Paul Sartre, uma cultura da alteridade: filosofia e literatura. Universidade Nova de Lisboa, 2005, p. 277-290.

. Linguagem e discurso. Lisboa: INCM, 2003.

. Reasons of violence. Violence of reason: an interpretation based on Eric Weil's core paradox. In: AURÉLIO, D. P. and PROENÇA, J. (Org.). Terrorism: Politics, Religion, Literature. Cambridge: Cambridge Scholars Publishing, 2011.

BURBIDGEM, J. Historical Dictionary of Hegelian Philosophy. Lanham, Maryland: Scarecrow Press, 2008.

CANIVEZ, P. O kantismo de Eric Weil. Argumentos 6/11 (2014), p. 9-28.

CASTELO BRANCO, J.; COSTESKI, E. Observações sobre o hegelianismo de Éric Weil. In WEIL, E. Hegel e nós. Caxias do Sul: EDUCS, 2019, p. 17-34.

CHÂTELET, F. Chronique des idées perdues. Paris: Stock, 1977.

ÉTIEMBLE, R. Dialectique matérialiste et dialectique taoiste. L'Arche 11 (1945), p. 62-82.

FRANCHINI, R. La logica dela filosofia. Napoli: Giannini, 1971.

JARCZYK, G. - LABARRIÈRE, P.-J. De Kojève à Hegel. 150 ans de pensée hégélienne en France. Paris: Albin Michel, 1996.

KOJÈVE, A. Le Concept, le Temps et le Discours. Paris: Gallimard, 1983.

LÉVINAS, E. En découvrant l'existence avec Husserl et Heidegger. Paris: Vrin, 2006.

MATTOS, C. Eric Weil - Philosophie politique. Paris: Vrin, 1956. Revista Brasileira de Filosofia 8/2 (1958), p. 267-268.

PARASILITI, S. Le categorie post-hegeliane nella Logique de la philosophie. In

SARTRE, J.-P. Matérialisme et révolution I. Le mythe révolutionnaire. Les Temps Modernes 9 SICHIROLLO, L. (Org.). Eric Weil. Urbino: QuattroVenti, 1989, p. 59-98. (1946), p. 1537-1563.

. Matérialisme et révolution II. Les Temps Modernes 10 (1946), p. 1-32.

PATRON, S. Préface. In BATAILLE, G.; WEIL, E. À en-tête de Critique. Correspondance, 1946-1951. Paris: Lignes, 2014. 
PERINE, M. Filosofia e violência. São Paulo: Loyola, 2013.

QUILLIEN, J. Eric Weil et notre temps. In QUILLIEN, J. - KIRSCHER, G. (Edd). Cahiers Eric Weil IV. Septentrion: Villeneuve d'Ascq, 1996.

RICEUUR, P. O conflito das interpretações. Porto: Rés, 1988.

. De l'Absolu à la Sagesse par l'Action. In Actualité d'Eric Weil. Paris: Beauchesne, 1984, p. 407-423.

SALVUCCI, P. Il Kant di Weil. In SICHIROLLO, L. (Org.). Eric Weil. Urbino: Quattro Venti, 1989, p. 99-118.

SANS, G. Al crocevia della filosofia contemporanea. Roma: Gregorian \& Biblical Press, 2012.

SARTRE, J.-P. Critique de la raison dialectique. Précédé de Questions de méthode. Tome I. Paris: Gallimard, 1985.

Matérialisme et révolution I. Le mythe révolutionnaire. Les Temps Modernes 9 (1946), p. 1537-1563

Matérialisme et révolution II. Les Temps Modernes 10 (1946), p. 1-32.

SICHIROLLO, L. La dialettica degli antichi e dei moderni. Bologna: Il Mulino, 1997.

SINNERBRINK, R. Hegelianismo. [Trad. F. Creder]. Petrópolis: Vozes, 2017.

STRAUSS, L. On tyranny. Including the Strauss-Kojève correspondence. Chicago: University Chicago Press, 2000.

STRUMMIELLO, G. Filosofia e metafilosofia in Eric Weil. In: WEIL, E. Violenza e libertà. Milano: Mimesis, 2006, p. 101-119.

VALENTINI, F. La filosofia francese contemporanea. Milano: Feltrinelli, 1958.

WAHL, J. Tableu de la philosophie française. Paris: Gallimard, 1962.

WEIL, E. Ficin et Plotin. [Trad. A. Deligne; M. Engelmeier]. Paris: L'Harmattan, 2007. . Philosophie et réaité 1. Paris: Beauchesne, 2003.

. Philosophie et réaité 2. Paris: Beauchesne, 2003.

. Hegel et l'Etat. Paris: Vrin, 2002.

. Logique de la philosophie. Paris: Vrin, 1996.

. Philosophie politique. Paris: Vrin, 1996.

. Essais sur la philosophie, la démocratie et l'éducation. Lille: Presses Universitaires de Lille, 1993.

. Essais et conférences 1. Paris: Vrin, 1991.

. L'avenir de la philosophie. In QUILLIEN, J. (Org.), Cahiers Eric Weil I. Lille:

Presses Universitaires de Lille, 1987, p. 9-21.

. Violence et langage. In QUILLIEN, J. (Org.), Cahiers Eric Weil I. Lille: Presses Universitaires de Lille, 1987, p. 23-32. 
La philosophie de Pietro Pomponazzi. Pic de la Mirandole et la critique de l'astrologie. [Trad. G. Kircher; J. Quillien]. Vrin, Paris, 1985.

. Deux textes d'Eric Weil: I. Contre l'occultisme. II. Pic de la Mirandole et la critique à l'astrologie. Archives de Philosophie 48/4 (1985), p. 563-573.

Marx et la liberte André Vène, Vie et doctrine de Karl Marx. Critique 2 (1947), p. 68-75.

À propos du matérialisme dialectique. Étiemble, Dialectique materialiste et Dialectique taoiste. Critique 1 (1946) p. 83-90.

Endereço dos Autores:

Judikael Castelo Branco

Residencial Graciosa Apto. 501

Quadra 06 - Lt 01 - Orla 14 - Alameda 05

Plano Diretor Sul

77026-005 Palmas - TO

judikael79@hotmail.com

Evanildo Costeski

Rua Ministro Joaquim Bastos, 471 - Ap. 1901

Bairro de Fática

60415-040 Fortaleza - CE

evanildoc@uol.com.br 